\title{
Natureza, razão e sentimento: a paisagem oitocentista brasileira em Viagem pelo Brasil, de Spix e Martius $^{\mathrm{I}}$
}

Ana Paula Carvalho

\section{Resumo:}

Este trabalho visa realizar, através da obra Viagem pelo Brasil: I8I7-I820, de Spix e Martius, uma análise sobre estes viajantes do século XIX. Ainda imbuídos do espírito iluminista, estes naturalistas buscavam descrever na sua totalidade o que viam. A natureza neste relato é analisada como fonte de riquezas científicas e econômicas, mas se estabelece também uma afinidade afetiva, típica do Naturgefühl. Este fato, juntamente com a influência que Humboldt teve nos jovens naturalistas, ratifica como a dimensão romântica presente no relato evidencia a intenção dos autores em ligar a ciência à poesia. $O$ estilo científico e poético inaugurado por Humboldt nasce do anseio de alcançar a compreensão total da natureza. Para estes viajantes de inspiração romântica a potência e a grandiosidade do mundo natural só conseguiria ser compreendida através da comunhão entre a ciência e a estética.

Palavras-chave: Literatura de Viagem - Viagens Filosóficas - Naturgefühl

I O presente artigo originou-se do trabalho de conclusão da disciplina Tópicos Especiais I - O fantástico, o desconhecido e o revelado: viagens nos Impérios Ibéricos, Espanha e Portugal, séculos XVI-XVIII, ministrada em 20I2, sob a orientação do prof. Tiago Bonato. 
Natureza, razão e sentimento

Solo il naturalista merita stima, che sa descriverci e rappresentarci le cose più strane, esotiche, ciascuna nel suo luogo, nel suo ambiente, nell'elemento suo peculiare.

Goethe

\section{Novos interesses, novos olhares: um novo Brasil}

A chegada da família real portuguesa ao Brasil em I808 e a abertura dos portos naquele mesmo ano proporcionou a vinda de um grande fluxo de estrangeiros para o território. Antes desse evento, Portugal sempre procurou manter suas terras afastadas da ambição das nações europeias com o intuito de salvaguardar as potencialidades que a colônia luso-brasileira proporcionava à economia da metrópole.

O século XIX brasileiro foi marcado pela chegada de vários cientistas de diferentes nacionalidades. ${ }^{2}$ Naturalistas, zoólogos, geógrafos, artistas, entre outros, chegaram ao Brasil com a intenção de estudar um território que, até então, havia sido pouco explorado por estrangeiros sob o ponto de vista científico. ${ }^{3}$ Como se lê na obra dos naturalistas Spix e Martius, "Apesar, porém, dos grandes progressos no conhecimento dessa parte do mundo, oferece ela ainda vasto campo ao espírito pesquisador a fim de estender, com os descobrimentos, o círculo da ciência humana (SPIX; MARTIUS I98I, v. I, p. 25).

Outras motivações da viagem que podemos ainda citar são "a atração pelo exótico, a vontade de estudar a flora e a fauna dos trópicos e o interesse em descobrir novas espécies comercialmente exploráveis" (VEIGA 2009, p. 29I).

Nesse contexto, também conhecido como "novo descobrimento do Brasil" (KURY 200I, p. II7), está inserida a expedição dos cientistas Carl Friedrich

2 Diversos viajantes percorreram o Brasil durante o século XIX: Luccock, Caldcleugh, Walsh, Suzannet, Burmeister, Avé-Lallemant, Burton, Wells, Mawe, Eschwege, Freireyss, Saint-Hilaire, Pohl, Spix, Martius, Bunbury, Gardener, Castelnau e Agassiz (AUGUSTIN 2009, p. 59).

3 É bem verdade que a Coroa portuguesa havia feito um esforço em organizar diversas expedições científicas na segunda metade do século XVIII, que ficaram conhecidas como viagens filosóficas. A maior parte do material produzido pelos naturalistas, entretanto, permaneceu sem publicação na época. Recentemente as pesquisas sobre a temática aumentaram bastante, trazendo à tona várias problemáticas a respeito da história da ciência na América portuguesa setecentista. Ver, por exemplo, GRUZ; PEREIRA. In: FRAGOSO; FLORENTINO 2006. 
Phillip von Martius e Johann Baptist von Spix, que resultou na elaboração da obra Viagem pelo Brasil: I8I7-I820. De acordo com Lisboa (200I), Martius e Spix receberam esta incumbência da Real Academia de Ciências de Munique e contaram também com o apoio do rei da Baviera, Maximiliano José I.

Johann Baptist Spix nasceu em 8 de fevereiro de I78I, na Bavária. ${ }^{4}$ Em I800 concluiu o doutorado em filosofia e passou a se dedicar a outras áreas, como teologia, medicina e história natural. Em I806 recebeu uma bolsa de estudos para estudar zoologia em Paris. Segundo Günther Augustin, "durante a viagem no Brasil, Spix leu um vasto livro da natureza. Porém, restou pouco tempo para ele poder escrever seu livro [...]. Voltou com a saúde debilitada e morreu durante a redação do segundo volume de Viagem pelo Brasil, em I826" (AUGUSTIN 2009, p. 50).

Carl Friedrich Philipp von Martius nasceu em I7 de abril de I794 no estado da Bavária. Dedicou seus estudos a medicina e a botânica. Após o retorno da missão científica no Brasil, "entrou na Academia [de Giências de Munique] como membro regular e tornou-se diretor do jardim botânico. [...] Dedicou toda a sua vida aos estudos sobre o Brasil, que considerava como sua segunda pátria. Morreu em I3 de dezembro de I868" (id. ibid., pp. 50-5I).

A partir da leitura de alguns trechos de Viagem pelo Brasil, pretende-se analisar, nesse artigo, algumas questões referentes à permanência da herança iluminista no modo de perceber a natureza, que passa a ser revestida pelo utilitarismo correlacionado aos fins políticos e econômicos identificáveis nesse relato. Outro ponto importante da pesquisa diz respeito à forma como o romantismo influenciou a obra desses cientistas.

\section{A herança iluminista}

No que diz respeito à concepção de ciência, é possível perceber a intenção por parte desses naturalistas de construir um conhecimento universal a partir do estudo da natureza in totum. Spix e Martius percorreram cerca de dez mil quilômetros entre I8I7 e I820. Segundo Lisboa (200I), os naturalistas partiram do Rio de Janeiro e prosseguiram rumo a São Paulo e Minas Gerais, transpuseram as margens do rio São Francisco na fronteira com Goiás e depois voltaram para o litoral baiano. Da Bahia se deslocaram para o Noroeste até chegarem

4 Todas as informações sobre os naturalistas, neste e no próximo parágrafo, foram retiradas de AUGUSTIN 2009. 
a Belém. Dali prosseguiram até a fronteira da atual Colômbia e em seguida retornaram a Belém (LISBOA 200I, pp. 75-76).

Spix, como zoólogo, ficou encarregado de analisar o reino animal:

Nesse domínio, incluirá ele tudo que diz respeito ao homem, tanto indígena como imigrados: as diversidades, conforme os climas; o seu estado físico e espiritual etc.; a morfologia e a anatomia de todas as espécies de animais, dos inferiores aos superiores, os seus hábitos e instintos, a sua distribuição geográfica e migrações; e, igualmente, fará observações sobre os restos existentes embaixo da terra. (SPIX; MARTIUS I98I, v. I, p. 26)

Martius, botânico, assumiu a responsabilidade de pesquisar a flora tropical:

competia-lhe investigar aquelas formas que, pelo parentesco ou identidade com plantas de outros países, permitem concluir qual a pátria de origem [...]. Pretendia ele fazer essas pesquisas, levando em conta as relações climáticas e geológicas, e por essa razão estendê-las também aos membros do reino das plantas, tais como os musgos, liquens e cogumelos (SPIX; MARTIUS I98I, v. I, p. 26).

A Academia também solicitou que outras áreas das ciências naturais fossem abordadas, como a física, a mineralogia, a geologia, a população local e seus costumes. A pretensão de abarcar o número maior possível de áreas das ciências naturais com o intuito de alcançar o conhecimento universal não pode ser compreendida sem a devida correlação com a formação enciclopedista desses naturalistas. Pois, "seguindo os preceitos dos enciclopedistas, a história natural visava ocupar-se de toda a natureza, desde os astros até os minerais, passando pela fauna e flora, incluindo o homem" (LEITE apud LISBOA I995, p. 85). A catalogação e categorização de todo o mundo natural foi um dos motes do pensamento setecentista, que continuou presente século XIX adentro. Muitos projetos das academias de ciências eram demasiadamente vastos. Segundo Paul Hazard (I989), a Academia de Bordeaux, por exemplo, empreendeu um desmensurado projeto, em I7I9, que tinha por intuito escrever "a história da terra e de todas as modificações que nela se produziram, tanto gerais como particulares, quer por tremores de terra e inundações, quer por outras causas”. Além disso, pensava-se em fazer

uma descrição exata das modificações da terra e do mar, da formação ou desaparecimento de ilhas, rios, montanhas, vales, lagos, golfos, estreitos, cabos [...)] e também das obras feitas pela mão do homem que deram à terra um novo aspecto (HAZARD I989, p. I3I). 
As intenções da ciência do setecentos de conhecer, recolher, catalogar e sistematizar o mundo natural também tiveram espaço nas viagens oitocentistas. Segundo Pierre Berthiaume, era possível encontrar algumas peculiaridades nos relatos de viagem entre a segunda metade do século XVIII e a primeira metade do século XIX. A principal era a capacidade de mesclar interesses acadêmico- científicos com uma política estatal. Segundo o autor, a variedade de interesses que imbricavam essas expedições foi fruto de uma nova forma de perceber a viagem não mais como uma descoberta, mas como uma atividade de pesquisa (BERTHIAUME apud GUIMARÃES 2000, p. 394).

As Reais Academias de Giências, responsáveis pela seleção dos cientistas e organização das expedições, eram muitas vezes financiadas pelas Coroas dos Estados nacionais europeus. As autoridades percebiam nessas missões uma forma de obter o devido espaço para o próprio país no cenário científico internacional. Dessa forma,

academias nacionales de Ciencias, $[\ldots]$ se convertirían en una especie de órganos asesores del Rey, entre cuyas funciones no serán las menos importantes las destinadas a consagrar la obra de algunos hombres de ciencia y proporcionar el brillo que prestigiaba y legitimaba la acción política de la corona (LAFUENTE I987, p. 375).

O status científico proporcionado pelo descobrimento de novas espécies também foi apontado por Pereira (2002). Segundo ele, as expedições poderiam ser organizadas de modo a

apressar a recolha de "produtos da natureza" das diversas partes do Império, de maneira a catalogá-los o mais breve possível, o que renderia muitos dividendos acadêmicos e políticos, nesta corrida científica que se estabelecera entre as nações europeias. Recolher e dar a conhecer o maior número possível de espécies era uma questão de orgulho nacional (PEREIRA 2002, p. 30).

Pode-se perceber que Martius, quando asseverava que "a vocação dos germânicos seria conquistar os espaços e povos não europeus pelo espírito, pela ciência e pelo conhecimento" (LISBOA 2009, p. I90), buscava projetar a Real Academia de Ciências de Munique ao mesmo patamar de instituições científicas de outros países como França, Inglaterra e Áustria, que já contavam com um lugar de destaque no campo científico internacional.

Inicialmente limitada aos exploradores e naturalistas portugueses, a natureza brasileira sempre despertou interesse aos olhos estrangeiros. Com a 
abertura dos portos, em I808, a riqueza natural do Brasil se tornou foco de interesse de outras nações europeias, que além do mérito científico almejavam a exploração dos produtos naturais para fins econômicos. Isso estava de acordo com os preceitos iluministas, uma vez que a ciência setecentista investiu na natureza de caráter utilitário, no qual o homem através do conhecimento seria capaz de valer-se dos elementos da natureza para fins terapêuticos e econômicos.

A ideia de aproveitar as potencialidades naturais do Brasil para fins econômicos fica evidente em alguns trechos do relato dos naturalistas:

Existia dantes, neste jardim, uma criação de cochonilhas sobre figueiras indianas, que estavam plantadas ao longo da margem; atualmente, porém, ninguém em todo o Brasil se ocupa com este produto, que poderia vir a ser um ramo de negócio extremamente lucrativo (SPIX; MARTIUS I98I, v. I, p. 65).

E, mais adiante:

Existe também no país outro bicho-da-seda, que se encontra em abundância, sobretudo no Maranhão e no Pará, em um arbusto do gênero das Lauráceas, todavia não foi utilizado em parte alguma, embora de fácil cultivo; e o fio do seu casulo promete seda ainda mais brilhante que a europeia. O que, porém, poderia fornecer um ramo ainda mais lucrativo de cultura é a criação da cochonilha, porque vegeta aqui o Cactus coccinellifer, com o seu respectivo inseto, em muitos lugares da província de São Paulo, especialmente em campos ensolarados (SPIX; MARTIUS I98I, v. I, p. I44).

A partir do século XIX houve uma intensificação dessas redes de informação com o escopo de mapear as riquezas naturais e estudar suas possíveis utilizações. ${ }^{5}$ Nos trechos que seguem percebe-se a atenção com a qual estes naturalistas se voltaram para as plantas com propriedades medicinais.

Nas matas circunvizinhas da montanha e, segundo nos asseguraram, mesmo na proximidade daquele cafezal, viceja uma espécie de quina, que já desde alguns anos é exportada sob nome de "quina do Rio" e cuja eficácia nas febres intermitentes tem sido demonstrada pela experiência dos médicos práticos de Portugal (SPIX; MARTIUS I98I, v. I, p. 82).

5 Para uma discussão a respeito das redes de informação, ver DOMINGUES 200I, pp. 823-38. 
Mais adiante, sobre o mesmo tema:

Atribui ao vermelhão do urupê (Boletus sanguineus), que aparece de repente nas árvores podres e muitas vezes só dura um mês, virtude especial para estancar hemorragias uterinas; encontrou na madeira amarela da butua (Abuta rufescens) um indício para sua eficácia nas doenças do fígado; nas raízes em forma testicular da contra-erva (Dorstenia brasiliensis) e nas folhas cordiformes do coração-de-jesus (Mikania officinalis nob.) o sinal de propriedades fortificantes dos nervos e do coração, e considerava a grande e magnífica flor da Gomphrena officinalis nob. (SPIX; MARTIUS ig8I, v. I, p. I62).

A busca por plantas medicinais esteve presente em grande parte das expedições científicas do século XVIII-XIX. Além dos benefícios econômicos dessas plantas em terras europeias, certamente os cientistas não deixavam de se preocupar com as condições de saúde dos sertões e cidades do nascente Brasil oitocentista. Além disso, é claro, a discutida busca pela construção do conhecimento universal fez com que Spix e Martius reservassem espaço em seus diários para os medicamentos naturais.

\section{Naturgefühl}

Além dos aspectos políticos e econômicos que impulsionaram essa expedição, algumas características típicas do romantismo influenciaram a escrita e o modo de perceber a natureza. Humboldt, naturalista, explorador e botânico, foi uma influência marcante para Spix e Martius. Segundo Kohlhepp (2006), a expedição científica organizada por Humboldt entre I799 e I804 percorreu boa parte da América espanhola, passando pelos vice-reinos do Peru, Nova Granada e Nova Espanha e ainda pela ilha de Cuba. A viagem fez do naturalista um grande conhecedor dos aspectos físicos, econômicos, políticos e sociais da América Latina.

Spix e Martius, assim como Humboldt, acreditavam que homem e natureza se complementam, de modo que era impossível entender a paisagem natural sem que o sentimento humano fosse levado em conta. Dessa forma, a racionalidade divide espaço com o sentimento na descrição da paisagem natural e na análise científica.

Nas ilustrações da obra aqui abordada é possível perceber a intenção por parte dos autores de representar o homem como parte integrante da natureza, uma vez que ambos se complementam nas descrições. Pode-se perceber 
que, em alguns desenhos, os autores se concentraram em retratar seus objetos de estudo (fauna e flora) separados do contexto. O objetivo, nesses casos, é tentar fazer uma análise científica mais apurada, que se detenha nos detalhes do objeto - retirado da realidade para ser melhor descrito em seus aspectos morfológicos. Porém, em outras figuras, como na Cachoeira Araraquara (figura I), é visível a representação de uma paisagem completa, em todos os seus elementos, contando inclusive com a presença do homem como complemento dessa natureza. O homem assim é representado como parte intrínseca da natureza. O uso da imagem se torna uma ferramenta útil na tentativa de retratar, na totalidade, os fenômenos naturais observados. ${ }^{6}$

As ilustrações, além de conseguirem captar a relação homem natureza, auxiliam a compreensão daqueles que aqui não estiveram. Martius, em um trecho da obra Viagem pelo Brasil, diz:

É mais difícil retratar o caráter das jovens florestas brasileiras com palavras do que com imagens; e desse modo parece-nos já ter satisfeito ao benévolo leitor com a arte do pintor. Contudo aquele que deseje saber mais sobre a natureza destas florestas percorra a narração de nossa viagem e o nosso discurso acadêmico sobre a fisionomia das plantas no Brasil (MARTIUS apud KURY 200I, p. 867).

$\mathrm{Na}$ concepção de Martius imagem e texto se articulavam organicamente para produção de conhecimento científico. Para Kury (200I), o anseio em capturar os fenômenos naturais juntamente aos fatos culturais como parte integrante das paisagens fez com que os naturalistas do século XIX, além de recorrerem às imagens pictóricas, muitas vezes buscassem auxílio na literatura. Para Spix e Martius, o trabalho do naturalista não se limitava a catalogar de forma lineana a natureza. ${ }^{7}$ Segundo Lisboa (2009), o historiador da natureza mantém uma relação afetiva com o seu objeto de estudo. Este sentimento da natureza é definido como Naturgefühl. Humboldt foi precursor desse modo de pensar a natureza. Ele foi o primeiro a mesclar descrições científicas da natureza com um discurso estético. Em uma carta a Goethe, escreveu que:

6 Sobre a utilização de imagens junto das narrativas textuais, ver BONATO 2014.

7 Carl Linné publicou Systema Naturae [Sistema da natureza] em I735. Segundo Rómulo de Carvalho, a tentativa de Lineu com sua obra era classificar toda a natureza em três reinos: o vegetal, o animal e o mineral. Devido à intensa atividade científica setecentista, "a primeira edição, de I735, constava apenas de doze páginas. A última edição publicada em vida de Lineu, já constava de mil e quinhentas páginas" (CARVALHO ig87, p. 32). 


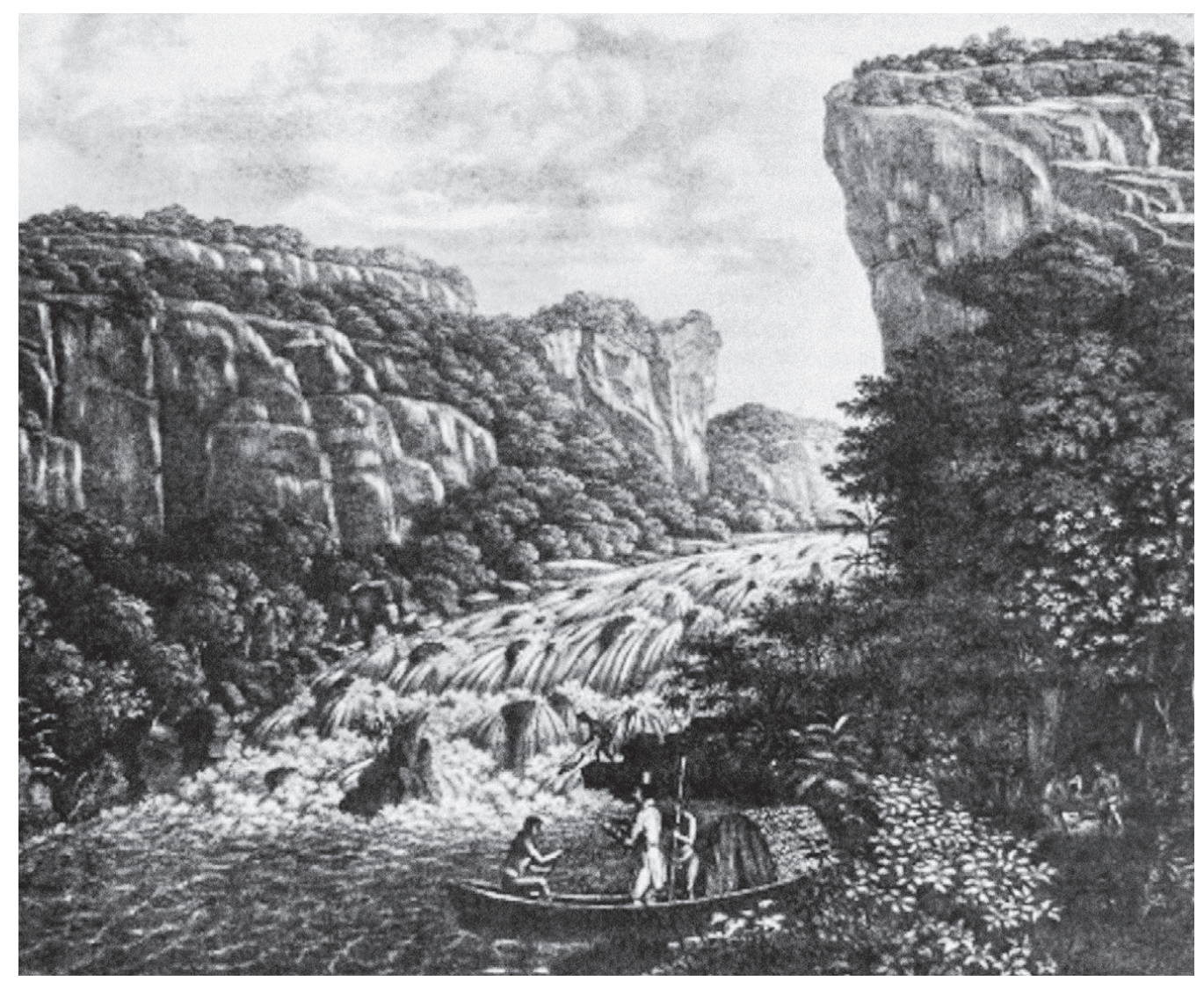

Figura I: Cachoeira Araraquara (SPIX; MARTIUS I98I, v. III, p. 238).

A natureza deve ser sentida; quem somente vê e abstrai pode dissecar plantas e animais no turbilhão do pulsar dos trópicos ardentes ao longo de toda uma vida, acreditando estar descrevendo a natureza, permanecendo, no entanto, eternamente alienado dela (HUMBOLDT apud LISBOA 2009, p. I82).

Assim, como Humboldt, que asseverava que o sentimento da natureza era indispensável para sua própria compreensão, Spix e Martius, imbuídos por esse sentimento da natureza, descreveram de forma científica e poética a paisagem natural do Brasil oitocentista:

Ao passo que o mundo tranquilo das plantas, iluminado aqui e ali por milhares de vaga-lumes como por enxame de estrelas volantes, com as suas exalações balsâmicas glorifica a noite, resplandece o horizonte incessantemente com os relâmpagos, elevando a alma em jubilosa admiração às estrelas que no firmamento cintilam em solene silêncio acima da terra e do mar, inspirando-a com noções de maravilhas sublimes (SPIX; MARTIUS I98I, v. I, pp. 58-60). 
A descrição dos sentimentos evocados pela natureza insere o discurso destes viajantes em uma perspectiva romântica que vai além da observação empírica. Na obra é comum encontrar trechos em que esboçam o próprio estado de espírito instigado pela natureza: "Não menos extraordinário que o reino das plantas é o dos animais que habitam as matas virgens. O naturalista para aí transportado pela primeira vez, não sabe o que mais admirar, se as formas, os coloridos ou as vozes dos animais" (id. ibid., p. 95). Esse sentimento de deslumbramento perante a natureza é visível também quando os naturalistas afirmam que: "todos esses magníficos produtos de terra tão nova combinam-se num quadro, que mantém o naturalista europeu num contínuo e alternado estado de assombro e de êxtase" (id. ibid.).

\section{Considerações finais}

As sensações de encantamento e sobressalto descritas pelos viajantes dão ao discurso científico uma ênfase que transcende a exatidão científica. O método lineano permaneceu como ponto cardinal para a compreensão do mundo natural, mas o Naturgefühl possibilitava a apreensão subjetiva e detalhada do objeto observado. Segundo Temístocles Cezar, no Brasil oitocentista "nem sempre ser poeta ou romancista era incompatível com ser historiador; e ir de um gênero ao outro era uma opção, não uma impossibilidade intelectual” (CEZAR apud OLIVEIRA 20IO, p. 47).

A obra Viagem pelo Brasil é um exemplo de como uma narrativa científica e fortemente influenciada pelos preceitos iluministas pode também ser considerado um trabalho poético, mesmo que mediado pela razão. Esta obra é fruto da síntese entre o saber científico e o Naturgefühl evocado pela beleza natural das paisagens. O estilo científico e poético inaugurado por Humboldt nasce do anseio de alcançar a compreensão total da natureza. Para estes viajantes de inspiração romântica, a potência e a grandiosidade do mundo natural só conseguiria ser compreendida através da comunhão entre a ciência e a estética.

\section{Referências bibliográficas}

AUGUSTIN, G. Literatura de viagem na época de Dom João VI. Belo Horizonte: UFMG, 2009.

BONATO, T. Viagens do olhar: relatos de viajantes e a construção do sertão nordestino (I783-I822). Guarapuava: Editora da Unicentro, 2014.

CARVALHO, R. de. A história natural em Portugal no séc. XVIII. Lisboa: Instituto de Cultura e Língua Portuguesa, I987. 
GRUZ, L. R. B.; PEREIRA, M. R. M. A história de uma ausência: os colonos cientistas da América portuguesa na historiografia brasileira. In: FRAGOSO, João; FLORENTINO, Manolo (Orgs.). Nas rotas do Império. Vitória: Dufes; Lisboa: Instituto de Investigação Científica Tropical, 2006.

DOMINGUES, A. Para um melhor conhecimento dos domínios coloniais: a constituição de redes de informação no Império português, em finais do setecentos. História, Ciências, Saúde, Manguinhos, v. 8, 200I, pp. 823-38. Suplemento.

GUIMARÃES, M. L. S. História e natureza em von Martius: esquadrinhando o Brasil para construir a nação. História, Ciências, Saúde, Manguinhos, v. 7, n. 2, jul.-out. 2000, pp. 389-4I0.

HAZARD, P. O pensamento europeu no século XVIII. Lisboa: Presença, I989.

KOHLHEPP, G. Descobertas científicas da Expedição de Alexander von Humboldt na América Espanhola (I799-I804) sob ponto de vista geográfico. Revista de Biologia e Ciências da Terra, v. 6, n. I, 2006, pp. 260-78.

KURY, L. Viajantes-naturalistas no Brasil oitocentista: experiência, relato e imagem. História, Ciências, Saúde, Manguinhos, v. 8, 200I, pp. 863-80. Suplemento.

LAFUENTE, A. Las expediciones científicas del setecientos y la nueva relación del científico con el Estado. Revista de Indias, v. XLVII, n. I80, I987.

LISBOA, K. Brasil dos naturalistas Spix e Martius. Revista Acervo, 22 nov. $201 \mathrm{I}$. Disponível em: 〈http://www2.an.gov.br/seer/index.php/info/article/view/77〉. Acesso em: I5 out. 2012.

MARTIUS, G. F. P.; SPIX, J. B. Viagem pelo Brasil. Belo Horizonte/São Paulo: Itatiaia/Edusp, I98I. 3 v. (I823-3I).

OLIVEIRA, M. G. Fazer história, escrever a história: sobre as figurações do historiador no Brasil oitocentista. Revista Brasileira de História, São Paulo, v. 30, n. 59, 20IO, pp. 37-52.

PEREIRA, M. R. M. Um jovem naturalista num ninho de cobras: a trajetória de João da Silva Feijó em Cabo Verde em finais do século XVIII. História: Questões \&Debates, Curitiba: Editora UFPR, n. 36, 2002, pp. 29-60.

TODOROV, T. As morais da história. Portugal: Europa-América, I99I.

VEIGA, J. E.; EHLERS, E. Diversidade biológica e dinamismo econômico no meio rural. In: MAY, Peter (Org.). Economia do meio ambiente: teoria e prática. 2. ed. Rio de Janeiro: Campus Elsevier, 2010, pp. 289-308.

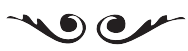

Ana Paula Carvalho - Graduanda em História pela Universidade Estadual do Centro-Oeste do Paraná.anapaularcb77@gmail.com 